\title{
Measuring Multidimensional Poverty According to National Definitions: Operationalising Target 1.2 of the Sustainable Development Goals
}

\author{
Marco Pomati ${ }^{1} \cdot$ Shailen Nandy ${ }^{1}$
}

Accepted: 30 September 2019 / Published online: 11 October 2019

(c) The Author(s) 2019

\begin{abstract}
The first Sustainable Development Goal (SDG) tasks countries with eradicating poverty in all its dimensions according to national definitions. This presents considerable challenges for poverty researchers and national statistical offices charged with collecting data to monitor progress on meeting of this ambitious target. Our paper focuses on how the different dimensions of poverty might be mapped out, and compared, within and across heterogeneous countries and societies, using a method called the Consensual Approach to poverty measurement. It explains how the approach can inform different poverty measurement frameworks (e.g. rights based, capabilities or deprivation of basic needs approaches), how it has already been used successfully across low, middle- and high-income countries and sets out some key lessons and future challenges. The paper uses data from the demographic and health surveys (DHS) and World Bank's Core Welfare Indicator Questionnaire surveys to demonstrate cross- and intra-national consensus about what constitutes minimally acceptable living standards across several countries in West Africa; we suggest that existing survey platforms, like national household income and expenditure surveys, DHS or even UNICEF's Multiple Indicator Cluster Surveys could (with minor additions) be used to apply the Consensual Approach to measure multidimensional poverty in children and adults across countries, and thus aid reporting for the SDGs.
\end{abstract}

Keywords Multidimensional poverty $\cdot$ Household Surveys $\cdot$ Consensual poverty $\cdot$ Child poverty $\cdot$ Africa $\cdot$ Development

\section{Introduction}

The Millennium Development Goals (MDGs) succeeded in focussing and sustaining global attention on the issue of extreme poverty and its correlates in low- and middle-income countries (LMICs). However, the 2015 target date passed, with UN agencies, national governments, and civil society organisations reporting varying degrees of success in meeting

Marco Pomati

PomatiM@Cardiff.ac.uk

1 School of Social Sciences, Cardiff University, Cardiff, UK 
the targets set; unsurprisingly, not all MDGs were met everywhere, and there were differing rates of progress and success. With regards the first MDG, the eradication of extreme poverty and hunger, ${ }^{1}$ success at a global level was heralded (Sala-i-Martin and Pinkovskiy 2010; Chandy and Gertz 2011; United Nations 2015), not least because of the remarkable rate of progress in East Asia (China) over the last 30 years. Sceptics, though, have questioned the metrics used (Vandemoortele 2002; Townsend et al. 2006; Reddy and Pogge 2010) arguing that poverty estimates in many poor countries are of questionable reliability, given the quality and availability of data (Jerven 2013). In addition to this is the more fundamental issue of how poverty is conceived, defined and measured for such goals. This paper reviews several approaches currently used to assess multidimensional poverty and then presents in more detail one specific framework, the Consensual Approach. Using empirical data from the World Bank's Core Welfare Indicator Questionnaire (CWIQ) surveys and the DHS, we argue that the Consensual Approach has clear advantages when conceiving and defining multidimensional poverty, and also that it can inform other poverty measurement frameworks-e.g. ones which use rights based approaches or Sen's Capabilities framework.

\section{Background: Evolving Definitions and Measures of Poverty}

The history of scientific research on poverty, conducted in rich and poor countries is long (Booth 1893; Rowntree 1901; Naoroji 1901). While earlier studies equated poverty with an insufficiency of resources needed to maintain minimal levels of subsistence (more absolutist notions of poverty), a significant body of academic work over the past half-century, by sociologists like Townsend (Townsend 1954, 1970, 1979) and economists like Sen (Sen 1987, 1999), has demonstrated how poverty is much more than simply being unable to feed oneself and one's family. People, wherever they are in the world, value the ability to participate in customary social activities and to be able to meet expected social norms (e.g. gift giving, celebrating important social events, etc.). Recognition of the importance and impact of exclusion from social norms and customary activities (Chase and Walker 2013) led to definitions of poverty expanding to incorporate elements of social participation which early studies neglected. These more relativist concepts and definitions of poverty acknowledge that it should be measured with reference to time and place, rather than only using an arbitrarily assigned low level of income to reflect people's abilities to cover their most basic of needs (Anand et al. 2010).

Official European definitions of poverty have long made clear this relativity; in 1975 the European Council defined poverty as "individuals or families whose resources are so small as to exclude them from the minimum acceptable way of life of the Member State in which they live" (Council Decision 1975). The definition was updated in 1985, with clarification that 'resources' were more than just financial: "the poor shall be taken to mean persons, families and groups of persons whose resources (material, cultural and social) are so limited as to exclude them from the minimal acceptable way of life in the Member state in which they live" (EEC 1985). Other international definitions of poverty, such as that adopted by 117 governments at the 1995 World Summit on Social Development (WSSD) (United Nations 1995) reflect the relative and broader nature of

${ }^{1}$ http://www.un.org/millenniumgoals/poverty.shtml. 
poverty, with reference to minimally acceptable standards of living. The WSSD defined 'overall poverty' as:

a lack of income and productive resources to ensure sustainable livelihoods; hunger and malnutrition; ill health; limited or lack of access to education and other basic services; increased morbidity and mortality from illness; homelessness and inadequate housing; unsafe environments and social discrimination and exclusion. It is also characterised by a lack of participation in decision-making and in civil, social and cultural life (United Nations 1995).

Equally applicable to both high- and low-income countries, it provides the theoretical and methodological basis for comparable, relative measures of poverty. It also makes clear that access to basic services for education and health should be reflected in any measure, thus expanding the idea of resources beyond those owned or possessed by households.

Despite these advances, it remains the case that many studies and official measures of poverty in low income countries continue to rely on minimal, or absolute, notions and measures (Iliffe 1987; Hall and Midgley 2004). Official poverty lines continue to use calorie-based monetary measures, based on 19th Century understandings of people's minimum nutritional needs, and so do not reflect important non-material, social or participatory dimensions of poverty, or even the need for an adequate and nutritionally-balanced diet. Studies often have to make heroic-assumptions about data collected about economic activity which are known to be seriously flawed in many countries (Jerven 2013). Thus, it remains generally the case that poverty research in rich countries adopt a relativist approach, with broader definitions and notions of poverty, while those conducted in Africa and Asia continue to rely on more absolutist approaches and indicators, with lower thresholds devised for quite different contexts and times.

Since 2000, however, there have been notable efforts made to expand the definition and measurement of poverty in low income countries. The World Bank's Voices of the Poor report (Narayan et al. 2000) highlighted the complex nature of poverty, as did other studies using relative and non-monetary measures (Statistics South Africa 2012; INSAE 2007; Kingdon and Knight 2006; Klasen 2000; Sahn and Younger 2010; Gordon and Nandy 2012; Nandy and Pomati 2015; Alkire and Santos 2014). Growing use has been made of welfare outcome indicators to reflect people's living conditions in the contexts of poverty (Alkire and Santos 2010). As such, measures that reflect the quality of peoples' dwellings, levels of overcrowding, access to basic services like water, sanitation, healthcare and education, all of which are central to internationally accepted definitions of poverty, now form the basis of many national and international poverty studies, like UNICEF's Global Study of Child Poverty and Disparities (Fajth et al. 2012) run in over 45 countries. Similarly, the Multidimensional Poverty Index (MPI) developed by the Oxford Poverty and Human Development Initiative (OPHI), uses household and individual-level data about people's health (child mortality and nutrition), education (years of schooling and school attendance) and ownership of household assets to rank and compare countries (Alkire and Santos 2010). OPHI is working with national statistical agencies to broaden its original focus, and to incorporate aspects such as having access to bank accounts and the internet, secure employment, and personal security (UNDP 2019; NSIA 2019). This widening of definitions and broadening of measures means that poverty is now reflected in a more nuanced manner, with researchers able to use a variety of methods and tools to reflect its different dimensions. Researchers are also using micro-level qualitative techniques, like focus groups and small community surveys (e.g. Baffoe and Matsuda 2017a, b) to generate 
information about contextual aspects of livelihoods which can complement larger, surveybased assessments.

Researchers and policy makers acknowledge the value of moving beyond a reliance solely on money-metric measures (World Bank 2016). Extreme poverty, for the purposes of the MDGs, was assessed using the World Bank's so-called 'Dollar a day' indicator, and a similar approach is again being taken for the first SDG. SDG 1.2 however is more ambitious in its aim to halve the proportion of men, women and children of all ages living in poverty in all its dimensions, according to national definitions. SDG 1.2 presents an opportunity to fundamentally change the way global poverty is conceptualised and assessed. Not only does it call for separate estimates for children and adults, but it explicitly requires poverty be reflected more broadly, in all its dimensions and importantly, according to national definitions. ${ }^{2}$ It acknowledges that poverty is both multidimensional and relative.

A careful reading of SDG 1.2 raises two conceptual challenges for any applied measure of multidimensional poverty. The first is how to establish "all" of the possible dimensions of poverty and the second is how to analyse multidimensional poverty as a single construct when, by definition, it is made up of multiple dimensions. The latter challenge is currently the focus of much of the academic literature, with two main approaches central to the measurement of to relative poverty ${ }^{3}$ : Townsend's idea of relative deprivation (Townsend 1979) and Sen's Capabilities Approach (Sen 1999). Each tradition and related methodological developments have led to different answers to questions on how a range of indicators can be empirically selected and aggregated into a single indicator (for recent examples of the relative deprivation approach see Nandy and Pomati 2015; Guio et al. 2017 and for one example inspired by the Capability Approach see Alkire and Santos 2014).

The first challenge, of how to establish a list of "all" of the dimensions of poverty, paradoxically is the less explored of the two (Gursky and Kanbur 2006), particularly in middle- and low-income countries. This is the focus of our paper. We argue that addressing this issue separately from that of aggregation is important in order to provide a platform for dialogue and an appreciation of the different understandings and definitions of poverty. Establishing consensus about what is important and what is less so, is critical for any measure or estimate of poverty. Given the drive by researchers and institutions to widen the definition of poverty, it is important to develop a clear research strategy that can lead to the systematic collection of data which reflects the public's understanding for a truly national definition of poverty. Above we have provided examples of approaches such as the MPI which do not attempt to establish consensus and have instead relied on national experts and the availability of indicators in nationally representative surveys like DHS and MICS to guide the selection of their indicators. In contrast, some researchers have used focus groups to develop an understanding of the dimensions of poverty from the ground up, but for a range of reasons they either do not corroborate their findings using nationally representative surveys, or they have applied a broader focus on living standards and livelihoods rather

\footnotetext{
2 The SDGs do not specify what constitute 'national definitions'; we agree with Valadez-Martínez et al. (2018, p. 700) that definitons "based on the consensual agreement of members of the public empowers citizens, involving them in the creation of new social indicators and enabling them to reflect on and define the goods and services needed to achieve a dignified standard of living".

3 There are a wide range of poverty analysis frameworks (for a thorough review see Boltvinik 1998). Here we focus particularly on the two methodologies which have been used most widely for the measurement of relative deprivation across different countries.
} 
than just concentrating on defining poverty. Establishing consensus is indeed a rather difficult enterprise, and we now consider studies that have attempted this.

\section{Ascertaining Consensus}

An early systematic attempt to find out which goods and activities were valued by the general public for the purposes of poverty measurement stemmed from a reaction to Townsend's pioneering work (Townsend 1979). He had argued that poverty meant 'lacking the resources to obtain the types of diet, participate in the activities and the living conditions and amenities which are customary, or at least widely encouraged or approved of in the societies in which they belong' (Townsend 1979, p. 31). Townsend and colleagues drew up a list of items and activities using their own ideas of needs, and then put them to the general public (Piachaud 1987). Building on this, and with recognition of criticisms about an 'expert-led approach', Mack and Lansley (1985) developed and applied what is now known as the Consensual Approach (CA). Their aim was to seek public consensus about what was an unacceptable standard of living in the UK, and to discover if anyone fell below that publicly defined standard. Their contribution, and methodological innovation, was to give the public a voice in the process of defining what poverty was, and in doing so, suggesting how it might be measured. They demonstrated how the public was unanimous on the need for measures of poverty and minimum standards of living to go beyond basic levels of food and shelter, to include elements such as social activities and cultural/civic participation. Using focus groups with a range of publics to devise a list of items and activities that everyone in the UK should be able to have or do. Mack and Lansley developed a module of questions for use in nationally representative surveys that asked respondents which items/activities they considered "were necessary and which all people should be able to afford, and which they should not have to do without". Respondents were also asked whether they owned/did the items/activities, and if not, if it was because they did not want them, or because they could not afford them. Those who could not afford an item/necessity identified by a majority of the population as necessary or essential, were counted as deprived, with the total number of deprivations giving each respondent a score on an index of material deprivation (Gordon and Townsend 2000, pp. 76-79). As shown in Fig. 1, the Consensual Approach thus has two initial interrelated stages: first, establishing consensus about a list of Socially Perceived Necessities (SPNs), and second showing the extent to which the people cannot afford these SPNs and are thus deprived. A third stage entails statistical analysis to select valid and reliable items and the identification of the poverty line (Gordon and Townsend 2000; Guio et al. 2017). Our focus in this paper is specifically on the first stage, which we argue can enrich our understanding of the different dimensions of poverty.

Mack and Lansley's ground-breaking work inspired similar studies around the world (e.g. Halleröd 1995; Halleröd et al. 1997; Abe 2004; Saunders et al. 2008; Saunders 2011; Veladez-Martinez et al. 2018; Noble et al. 2004). Each subsequent study demonstrated that there was a high degree of consensus among the public about what constituted minimally acceptable standards of living, and that this consensus held across different social and economic groups. Mack and Lansley had shown that a significant proportion of people in Britain in 1985 could not afford serval SPNs, and that around one in seven people $[\sim 14 \%, 7.5$ million people] were deprived of three or more necessities (Mack and Lansley 1985). The establishment of SPNs through the Consensual Approach, however, was contested, with 


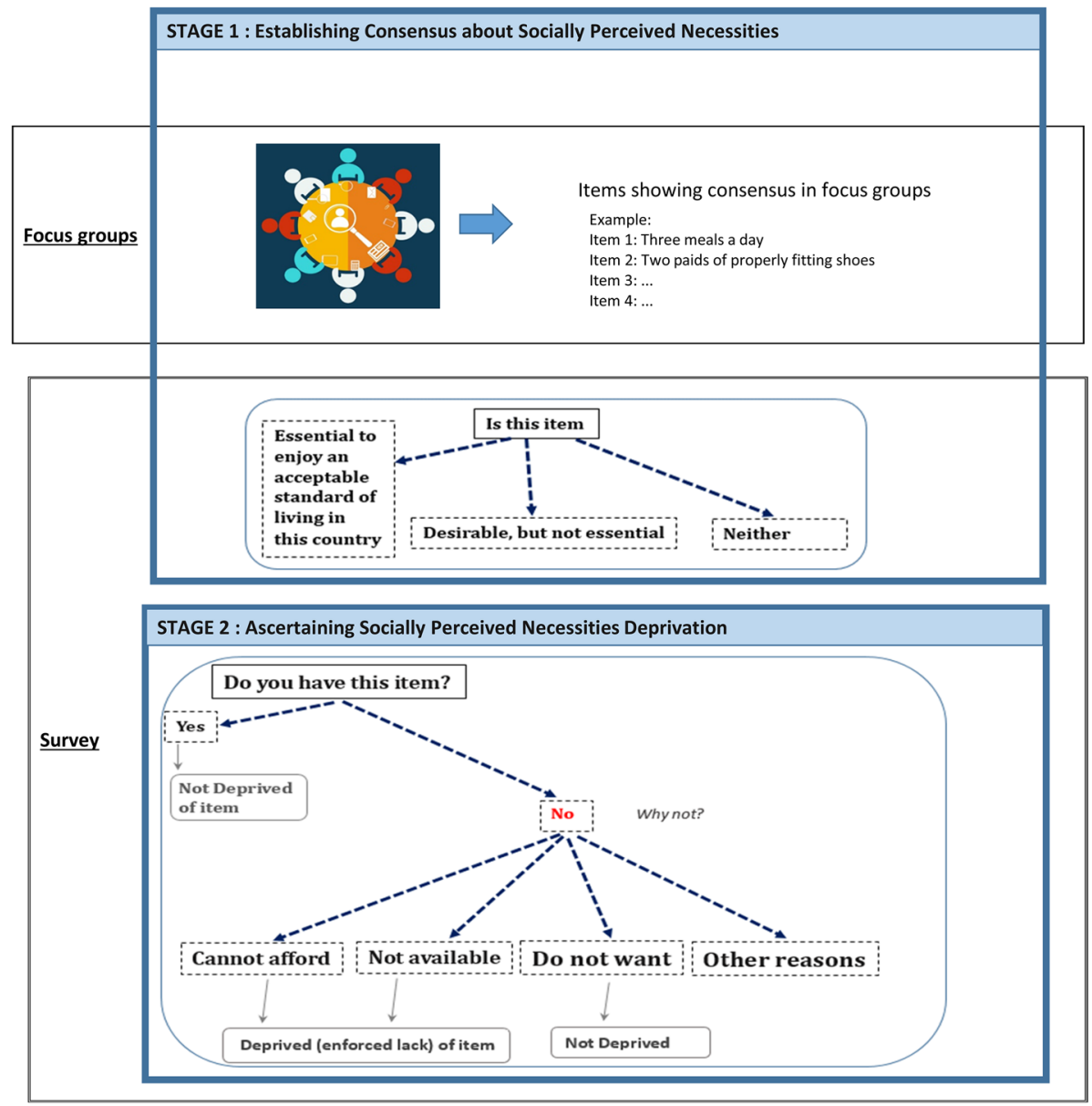

STAGE 3 : Data analysis: Validity Analysis, Reliability Analysis, Identification of poverty line

Fig. 1 Stages and methodologies of the consensual approach

critics raising three issues: (1) the way consensus was established; (2) the definition and understanding of consensus; and (3) the potential impact of adaptive preferences when asking the poor about what should constitute minimum standards for a population.

Walker (1987) raised the importance of transparency and dialogue in the establishment of a list of necessities, arguing that surveys, even when informed by focus groups, are limited in their ability to reflect socially perceived items; this can only really happen when respondents are provided an opportunity to '...listen to the views of others and to discuss with them...' (p. 219), and not through an individually administered questionnaire. He 
recommended the use of qualitative techniques to validate the Consensual Approach and for establishing a definition of poverty. Walker advocated an iterative and in-depth qualitative approach, where dialogue is promoted and which, after several iterations, a consensus may emerge. It could be argued that as societies become wealthier, and more unequal as has occurred over the last 30 years (Alvaredo et al. 2018), and as new social norms and customs emerge, it may become more difficult to establish consensus about new 'needs', and so more in-depth exploratory studies would be beneficial. Walker's critique highlights the importance of providing opportunities for dialogue between respondents during the focus groups (or any other processes of deliberation). It serves as a reminder that the items and phrasing of the questions should be rigorously scrutinised, and the process made transparent to the public.

Use of the term 'consensus' was questioned by McKay (2004). He challenged the idea that the studies using the approach were able to demonstrate consensus suggesting instead that 'majoritarian' was a more accurate way of describing the method; McKay argued that consensus implies that a clear majority of respondents would identify exactly the same set of items as necessary or not necessary, whereas Mack and Lansley's approach has the more modest, and direct aim of establishing which items and activities are endorsed by the majority-a democratic approach, so to speak.

Lastly, critics raised concerns about the potential impact of adaptive preferences in determining the degree of consensus. The theory of adaptive preferences posits that people raised or living in poverty may have 'bounded horizons', and so have lower expectations of what they (and others) should have or be entitled to e.g. being able to receive an education, to gainful employment, to access treatment when ill, and support in times of need, etc.). These reduced expectations from some respondents (i.e. the poor) may thus result in an understating by society of what are the necessities of life for society; or as Nussbaum argues,

people's desires and preferences respond to their beliefs about norms and about their own opportunities. Thus people usually adjust their desires to reflect the level of their available possibilities... People from groups that have not, persistently, had access to education, or employment outside the home, may be slow to desire these things because they may not know what they are like or what they could possibly mean in lives like theirs (Nussbaum 1999: p. 11).

Accepting this would, in effect, exclude the poor and discourage demands for radical change or higher norms and standards. Bounded horizons, it is suggested, are a potential source of bias since it may lead to a constrained expression of what social norms really are or should be, rendering them unreliable. Adaptive preferences are undoubtedly an important issue for poverty research (Burchardt 2004; Wright and Noble 2013; Halleröd 2006; Nandy and Pomati 2015) but there remains a degree of uncertainty as to whether they operate universally or in particular contexts. It is therefore useful to explore whether adaptive preferences are indeed present, and whether they affect the determination of any list of SPNs; if they do not affect societal views of what is necessary for everyone, then every effort should be made to include the voices of the poor in determining poverty definitions and measures (Narayan et al. 2000; Noble et al. 2004).

Despite these concerns, it is hard to deny that establishing and agreeing a range of items (good and services) which people regardless of their education, social and cultural background endorse is desirable, as this would contribute to the articulation of an idea of poverty underpinned by the concepts of democracy and citizenship (Veit Wilson 1987). As explained above, the Consensual Approach has been used in conjunction with Townsend's 
theory of relative deprivation but there is no reason why other approaches could not also apply it consistently. For example, supporters of Sen's Capabilities approach could use it to ascertain the particular 'freedoms' people value (capabilities) in a given country at a given time. Those advocating a rights-based approach (for empirical applications of this approach see Gordon et al. 2003; Chzhen and Ferrone 2017) could use it to inform definitions of what constitutes basic human rights and human needs, etc.

To date, the Consensual Approach has been applied successfully across high-income countries including all 28 European Union countries (EUROSTAT 2012), as well as in national studies in Belgium (Van den Bosch 2001), Finland (Halleröd et al. 2006), Sweden (Hallerod 1994, 1995), Japan (Abe and Pantazis 2013), South Korea (Kim and Nandy 2018) and Australia (Saunders 2011). Researchers have also applied it in Bangladesh (Mahbub 2007), Benin (Nandy and Pomati 2015), Vietnam (Davies and Smith 1998), Mali (Nteziyaremye and MkNelly 2001), Tanzania (Kaijage and Tibaijuka 1996), South Africa (Noble et al. 2004; Wright 2008), and Zimbabwe (Mtapuri 2011). Most recently (2016/2017) countries as diverse as the Solomon Islands and the Kingdom of Tonga in the South Pacific, and Uganda, have used it in national household surveys for national estimates of child and adult multidimensional poverty. Researchers have also used focus groups and surveys to develop gender-sensitive indicators of multidimensional poverty. For example, Wisor et al. (2016) explicitly solicited the views of poor men and women in Angola, Malawi, Mozambique, the Philippines, Nepal, Fiji and Indonesia with regards their conceptions and understanding of poverty. The resulting 'Individual Deprivation Measure' (IDM) is promoted as being "multidimensional, gender-sensitive, and inclusive in its understanding of poverty-consistent with the views of women and men with lived experience of deprivation" 4 and covers issues relating to food, water, shelter, health, education, energy/fuel, sanitation, relationships, clothing, violence, family planning, environment, voice, time use, and work (Hunt et al. 2017).

\section{Data and Methods}

We now demonstrate how the Approach can be used to demonstrate consensus about SPNs both across and within countries. We use individual-level data from the 2006 EMICOV/ DHS for Benin and data from Core Welfare Indicator Questionnaire (CWIQs) surveys for Liberia (2010), Mali (in 2006), Guinea (in 2007) and Gabon (in 2005) (Ajayi 2006). Respondents in each were asked if having certain things or being able to do a range of activities (e.g. being able to send children to school, having access to birth control, etc.) were necessary for 'a minimum standard of living'. They were then asked if they felt their needs with regards these items/activities were being met, and to what extent. ${ }^{5}$ Individuallevel CWIQ data for Gabon and Guinea were not available, and so we have used the percentages reported at the International Household Survey Network website (www.ihsn.org); because of this we were unable to perform more in-depth statistical analyses on Gabon and Guinea, and hence these countries feature only in our descriptive comparisons of the levels of endorsement of necessities across countries. For Benin, Liberia and Mali more in-depth analyses were possible, to see if and how public opinion about items/activities considered

\footnotetext{
4 www.individualdeprivationmeasure.org/idm/methodology/Accessed 18th June, 2019.

5 We would also like to acknowledge the kind support of staff in national statiss offices and the UNICEF country offices of Mali and Liberia in helping us access the data.
} 
Table 1 Datasets used in data analysis

\begin{tabular}{lcl}
\hline Dataset & Sample size & Further details \\
\hline Benin, 2006 DHS & 17,500 & Microdata obtained through DHS website \\
Gabon, 2005 CWIQ & 7900 & Percentages reported in Fig. 2 available on http://catalog.ihsn.org \\
Guinea, 2007 CWIQ & 7500 & \\
Liberia, 2010 CWIQ & 6000 & Microdata obtained with the help of statistical offices \\
Mali, 2006 CWIQ & 5000 & \\
\hline
\end{tabular}

essential varied across socio-economic characteristics. This was done by comparing percentages across groups using relative risk ratios (RRR). Confidence intervals (95\% CI) are provided for the RRR, with adjustments made for sample clustering and stratification. Full details on the CWIQ surveys can be obtained at the International Household Survey Network (IHSN,), where all metadata (questionnaires, sampling details, etc.) are deposited. Sample sizes ranged between 6000 cases in Mali to over 17,000 cases in Benin (See Table 1).

The surveys asked about peoples' living conditions, and about access to clothing, food, housing, health care, transport and work, education and leisure. These are all areas that any meaningful measure of multidimensional poverty should reflect. The 2016 Global Commission on Poverty set out a similar list of themes for any measure of poverty i.e. nutrition, health status, education, housing, access to work and personal security (World Bank 2016: p. 158).

The CWIQ/EMICOV surveys included two questions:

(1) Do you feel that the following items are necessary to maintain a minimum standard of living?

and

(2) Are you satisfied that your household meets minimum needs such as...[with regards the same list of items asked previously]?

These two questions are conceptually equivalent to the survey elements of Stage 1 and 2 in Fig. 1. Responses can be used to do several things; first, to gauge what people across countries think is necessary for a minimum standard of living; second, to show whether there is consensus across and within countries about what constitutes a minimum standard of living; and third, to show what proportion of people across a society are deprived of elements of a socially-defined minimum standard of living (Stage 2). In this paper we focus on the first two points, and acknowledge that these questions primarily reflect the needs and responses of adults, and thus miss the needs and rights of children. Even when questions address children's needs they do so from the point of view of parents/carers; the CWIQ and other platforms could benefit from incorporating lessons learned in more recent work which engages directly with children's own perceptions of poverty (e.g. Barnes and Wright 2012; Bradshaw 2016). Nevertheless, we argue that Question 1 is generally in line with the types of questions asked in Stage 1 (see Fig. 1) of the Consensual Approach surveys. For example, the Consensual Approach survey carried out in Uganda (see Appendix) asked respondents whether the items presented were essential in order to enjoy an acceptable standard of living in Uganda today. In contrast, the phrasing of Question 2 is somewhat different from the usual Consensual Approach one (see stage 2 in Fig. 1 and the Ugandan 


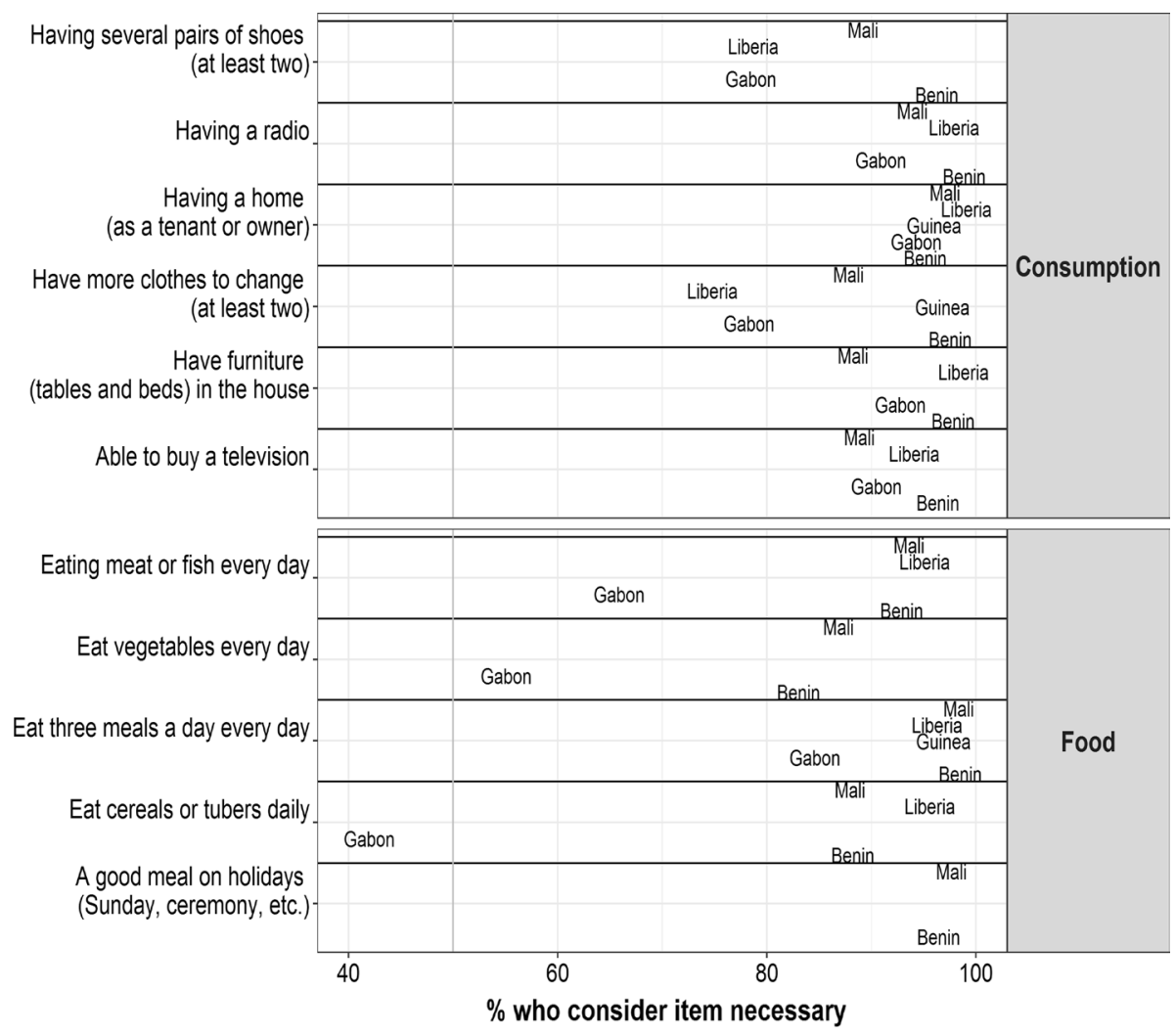

Fig. 2 Percentage in each country considering food and consumption items necessary to maintain a minumum standard of living. Source: Authors' calculation using CWIQ data

questionnaire in the Appendix), but as mentioned above in this paper we do not focus on this stage.

\section{Results}

We present basic descriptives of the proportion of adults in five west African countries -Benin, Liberia, Gabon, Guinea and Mali-responding to the CWIQ about whether item/ activities are necessary to maintain a minimum standard of living. Not all countries asked questions for all items, but respondents in all countries were asked about at least one item from the following categories: consumption, food, health, school and work, transport and basic services (water and electricity).

Figures 2 and 3 demonstrate that, at the national level across each of the countries, there is consensus (using a 50\% threshold a la Mack and Lansley 1985). In most instances there is near unanimous agreement about what items and activities contribute to a minimum standard of living. Over $70 \%$ of respondents report that all of these items are necessities. The single exception is Gabon, where less than 50\% reported that being able to eat cereals/ tubers/rice every day was not necessary. However, more than $50 \%$ in Gabon agreed that they should be able to afford vegetables or meat or fish every day, and more than $80 \%$ of 


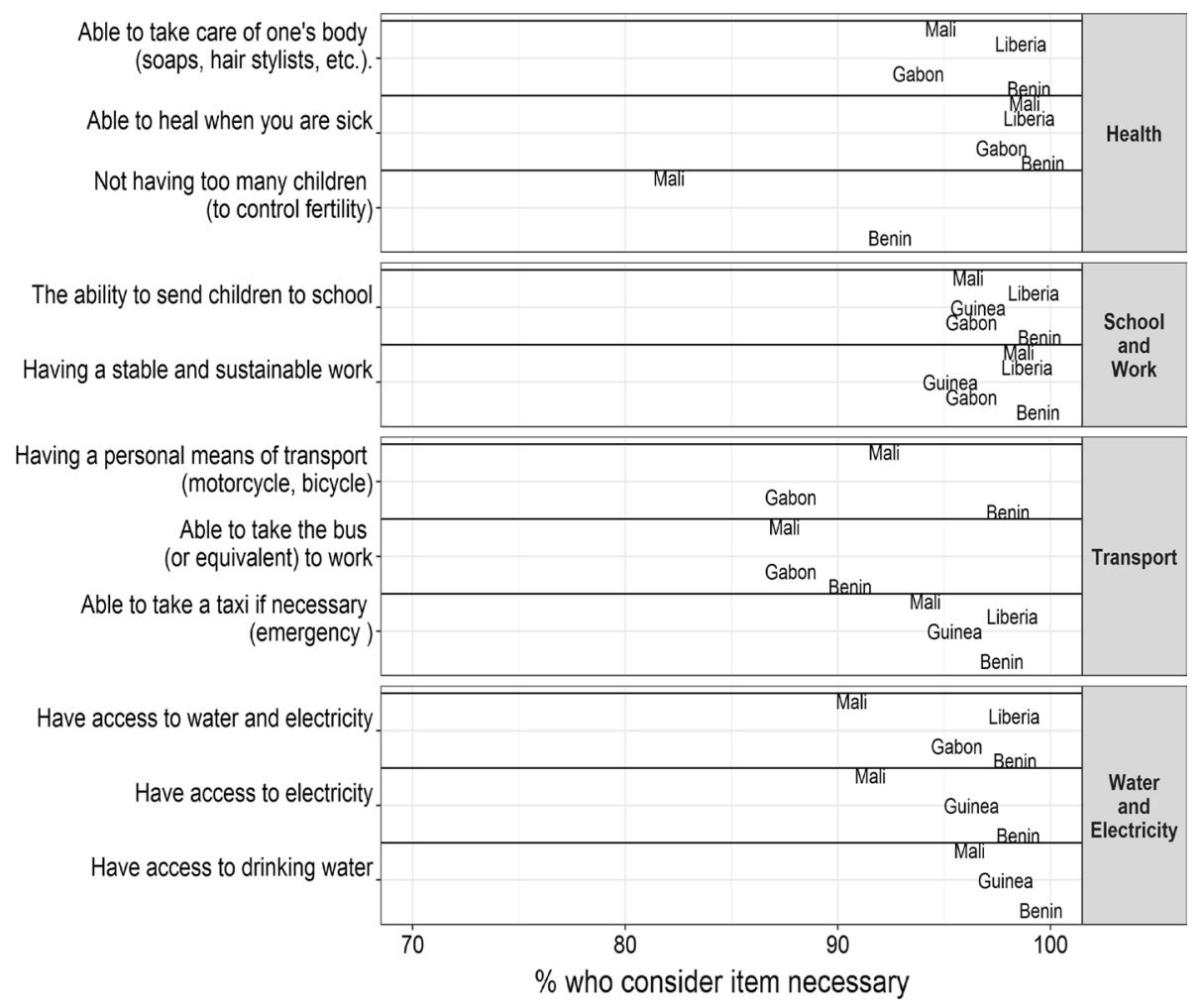

Fig. 3 Percentage in each country considering non-food and consumption items necessary to maintain a minimum standard of living. Source: Authors' calculation using CWIQ data

respondents in all five countries believed they should be able to afford three meals a day every day.

While consensus across countries is evident, it is also important that there is consensus within countries, across geographic and socio-economic groups. The complete micro-data for Gabon and Guinea (with subnational geographic and socio-economic variables) were unavailable, so we use data from Mali, Liberia and Benin to demonstrate how consensus holds across different groups within countries.

Figure 4 shows, for all three countries, the proportion of the public who consider items/ activities as necessary, according to age, education (Higher, No education, Preschool, Primary, Secondary or above) region of residence, and whether people live in rural or urban areas (rural inhabitants in these countries are generally poorer). For Liberia and Benin, we also consider agreement by ethnicity and religion. ${ }^{6}$ For each of these groups we look

\footnotetext{
${ }^{6}$ Based on the available data for Benin we consider the following categories for religion: Traditional (Vodoun), Other traditional, Islam, Catholic, Protestant methodist, Other protestant, "Celeste", Other christians, Other religions, No religion). We also consider the following ethnicities/nationalities: Adja and related, Barbia and related, Dendi and related, Fon and related, Yoa, Lokpa and related, Betamari and related, Peulh and related, Yoruba and related, Countries bordering Benin, Other countries, Other.

For Liberia we consider the following religions: Christian, Muslim, Traditional African religion, other religion, no religion and the following ethnicities: Bassa, Belle, Dey, Gbandi, Gio, Gola, Grebo, Kpelle, Kissi, Krahn, Kru, Lorma, Mandingo, Mano, Mende, Sapo, Vai, Naturalized Liberian,Congo Liberian/ American Liberia. More details are available below Fig. 4.
} 


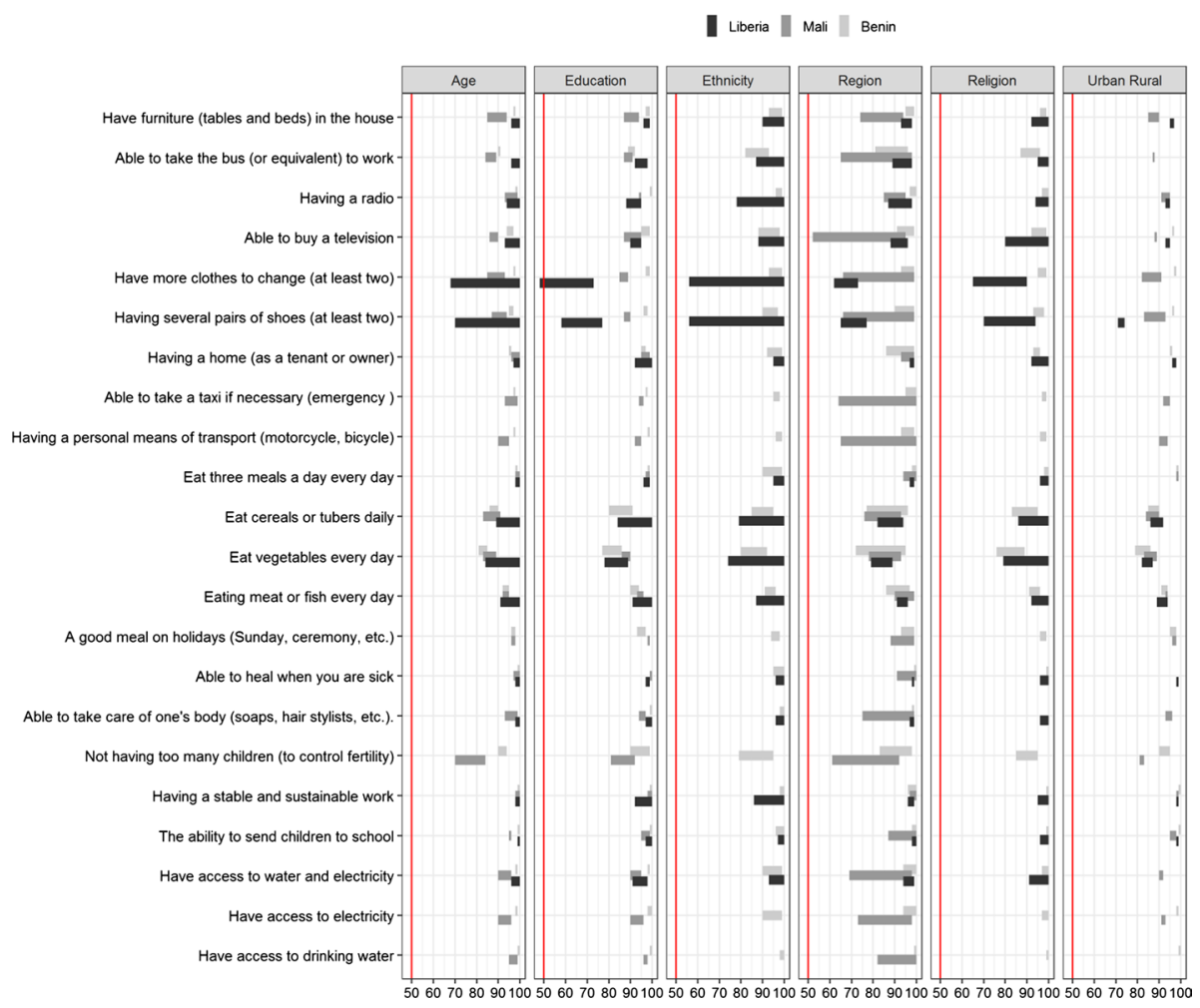

Fig. 4 Sub-national Consensus in Mali, Benin and Liberia.Bars range indicate lowest and maximum category agreement. Source: Authors' calcualtions on CWIQ data

at the range of minimum and maximum endorsement of each item as a necessity. The left end of each bar therefore represents the lowest level of endorsement, while the right end represents the highest. The bars represent the range of responses to the question about individual items being necessary; short bars represent greater agreement in responses, and long bars a greater difference in responses. For example, in Fig. 4, the largest difference in Benin is found with regards being able to have vegetables every day; where the proportion of respondents thinking this to be essential ranging from $72 \%$ in the region of Collines to nearly all respondents $(95 \%)$ in Alibori (labels omitted for the purposes of illustration). By omitting labels of regions and other groups in Fig. 4 we can focus more easily on (i) the degree of variation (and lack of), (ii) on the minimum levels of endorsement, and (iii) where the greatest differences lie. In Mali, the regional variation is greater for some items (as shown by the longer bar) like being able to buy a television: around half (52\%) of respondents in Gao thought this necessary, compared to nearly everyone (95\%) in Bamako. Liberia shows less regional variation, but more differences by ethnicity for some of the items around clothing: $56 \%$ of Krahn respondents endorse having at least two pairs of shoes and the same percentage endorse having at least two sets of clothes. Moreover, $48 \%$ 
of respondents with 'no education' endorse having at least two set of clothes to change, compared to $73 \%$ of those with university education; this is the only item which, when disaggregated by all these characteristics presents one group with agreement below $50 \%$. Except for the clothing items in Liberia, variation according to whether the household is in an urban or rural area, religion, age and education is general low across all three countries.

While some variation is natural, it is minimal in Mali and Benin, especially when we consider potential differences in outlook and living conditions of adults of different ages, education levels, and rural-urban place of residence. The source of greatest variation is geographic region; the longer bars in Mali suggest greater differences between regions about what items are necessary for a minimum standard of living. Liberia shows considerably more variation, particularly with regards items like shoes and clothes. However, what is most important to note is that, with the exception of having two items of clothing, in no instance do any bars go below the $50 \%$ mark; this means most people, in these countries, be they young or old, educated or not, living in a rural or urban setting, from different ethnic backgrounds and practicing different religions, think these items are important. We consider this evidence of public consensus about what constitutes necessities for a minimum standard of living.

We now turn to the issue of adaptive preferences and the potential for biasing population-defined norms and standards for poverty measurement and analysis. CWIQ data can be used to group respondents into self-reported 'poor' and 'non-poor' groups-e.g. respondents who report their income as being unstable versus those who do not, those who report never being able to save money versus those who can, or those who see themselves as the poorest compared to their community versus those who see themselves as fairly rich or among the richest.

Figure 5 presents the relative risk ratios for different groups of poor and non-poor considering items to be necessities for a minimum standard of living, along with their $95 \%$ confidence intervals (CIs). Relative risk ratios (RRRs) show the probability, or risk, of one group (in our case the poorest group) thinking an item to be essential compared to another group. In our figures a relative risk of 2 means that the poorest group is twice as likely to consider the item as necessary compared to not poor group. Similarly, a relative risk of 0.5 implies the poorest group is half as likely to think of an item as being a necessity, etc. Where CIs cross 1 , there is no statistically significant difference between what poor and non-poor respondents consider to be a necessity. If adaptive preferences were present, then we would expect to see the 'poor' systematically less likely to think an item was a necessity. We would therefore expect to see most relative risks appear below 1.

Figure 5 shows there are hardly any statistically significant or sizeable differences in what is considered a necessity between respondents who reported as 'living well or reasonably well' and those who reported living 'with difficulty', and those in the top and bottom quintiles. Figure 6 also confirms there are few differences between those who self-report being able to save and those who go into debt, and between selfreported levels of family income stability. Most of the RRRs are very close to 1 and very few show statistically significant differences. For Mali and Benin, where they are statistically significant they are below 1.10 or above 0.90 , indicating very small differences in endorsement of items as necessities between respondents with different levels of living standards, whether objective or subjective. Liberia shows more variation than Mali and Benin for clothing items (shoes and new clothes). The largest group difference in proportions endorsing new clothes and shoes is in Liberia between those who see themselves in the top $20 \%$ and the bottom $20 \%$. Just over $60 \%$ of the richest are 

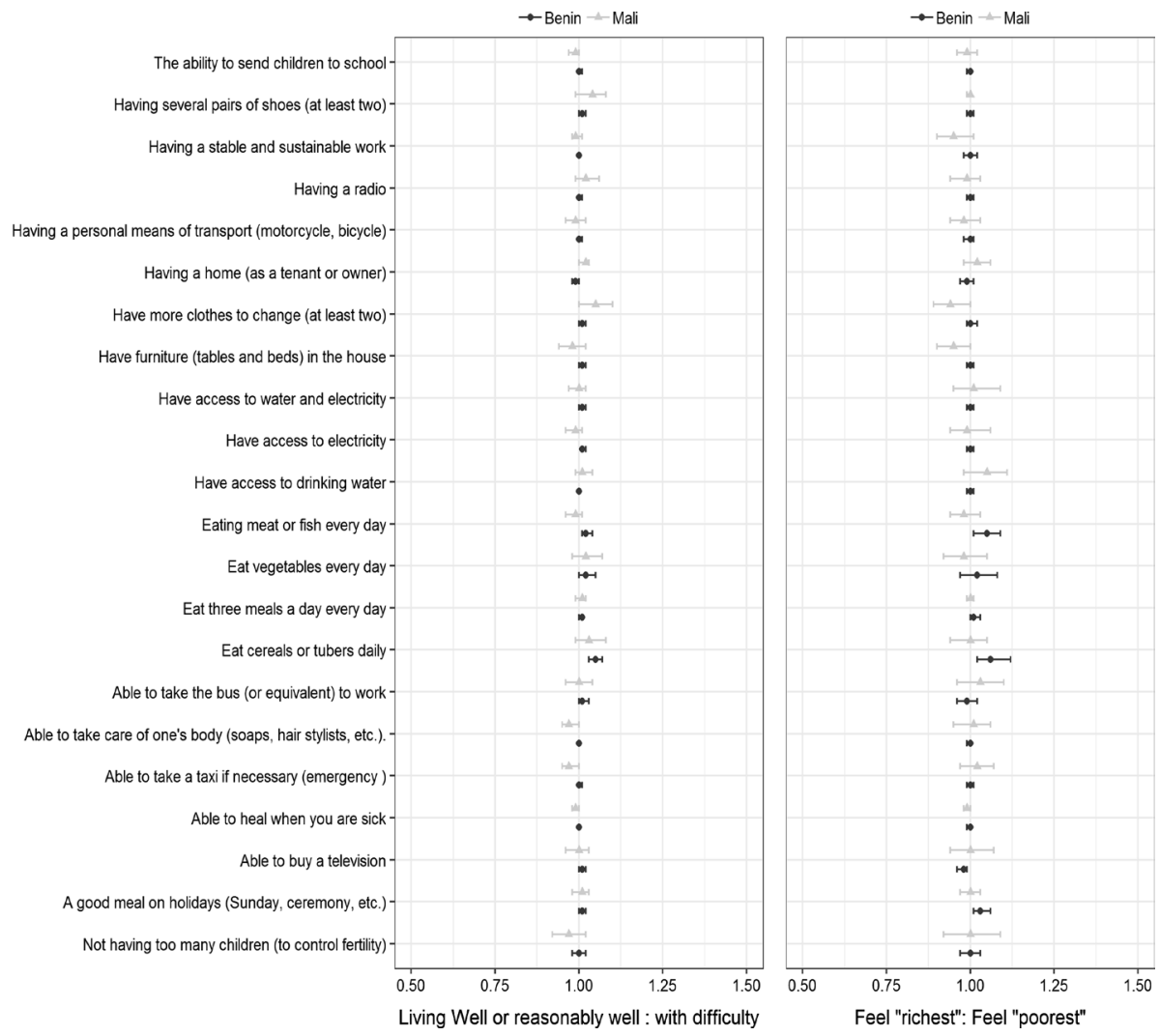

Fig. 5 Relative Risk ratios comparing the percentage of richer and poorer respondents who consider an item necessary to maintain a minimum standard of living. Source: Authors' calcualtions on CWIQ data

likely to endorse these items, compared to roughly $75 \%$ of those in the bottom quintile. These two items would require further analysis, although it is worth pointing out that more than $50 \%$ of each group endorses these items.

Finally, we repeated the same analysis using the number of items of which respondents are deprived. For the purposes of this analysis we considered those who were 'not satisfied at all' as deprived of that item (for a similar approach see Nandy and Pomati 2015). We then proceeded to look at whether those households that are more deprived are also less likely to think that some items are necessary than those with lower levels of deprivation. We compared households with no deprivations and five or more (Fig. 7) and repeated the same analysis comparing those with fewer than three and three or more deprivations (Fig. 8).

Our analysis, shows that although there are some differences more than $70 \%$ endorse all items and that for most items the differences are small (less than five percentage points difference between the less and more deprived groups). Overall, we find only very limited evidence of adaptive preferences for some items, and we do not think this constitutes enough evidence to undermine the Consensual Approach. 

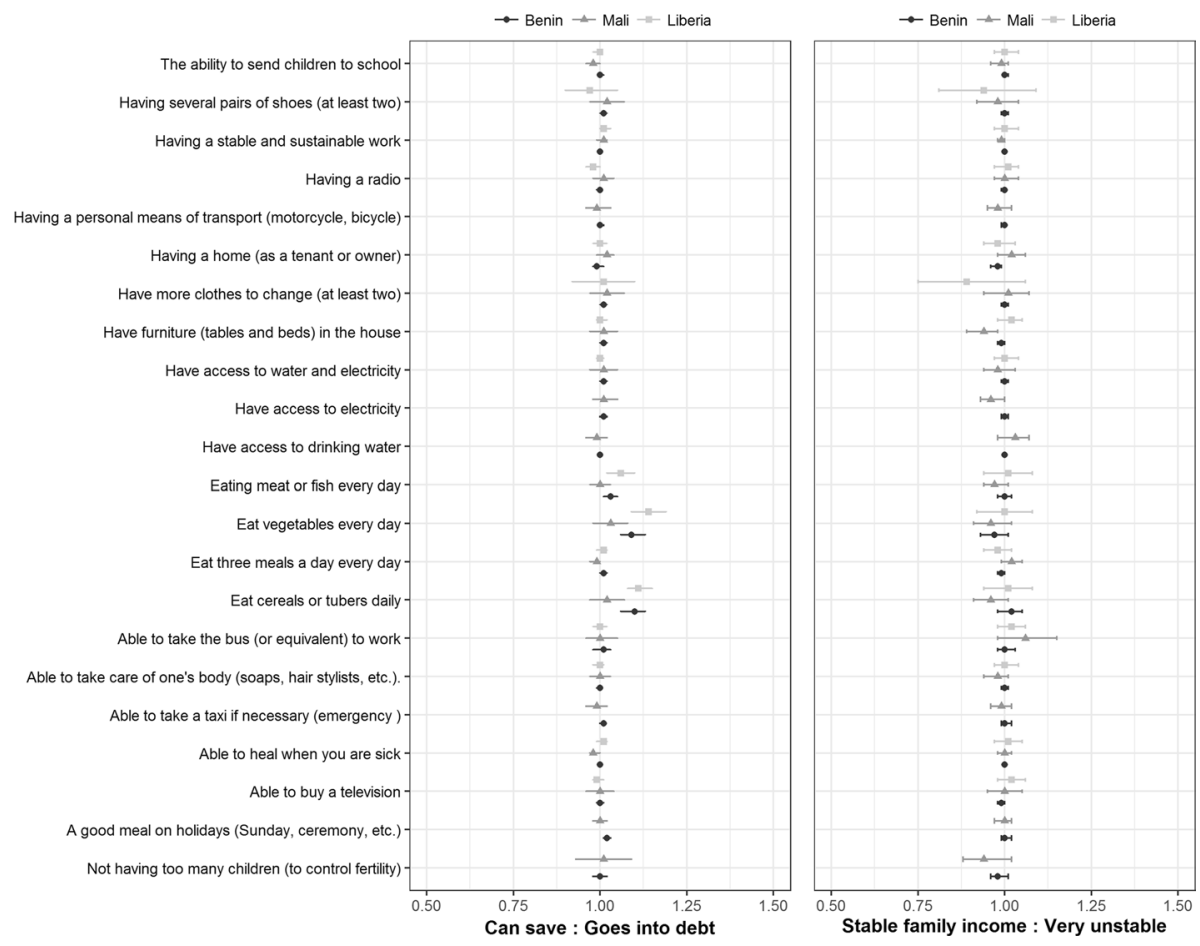

Fig. 6 Relative Risk ratios comparing the percentage of respondents with different levels of savings and financial stability who consider an item necessary to maintain a minimum standard of living. Source: Authors' calcualtions on CWIQ data

\section{Discussion}

We analysed the first stage of the Consensual Approach using CWIQ data from several west African countries, and argue that it can inform a range of other approaches to the measurement of poverty, specifically in understanding which dimensions of poverty are important to people across countries. Clearer methodological differences will no doubt emerge during the second stage (selection and aggregation), and these will reflect differing conceptions of poverty. For example, the Consensual Approach focuses on constructing a deprivation index, where a higher index score is considered a direct result of lower levels of resources (additivity), and that leads to accepted high levels of measurement validity and reliability (Nandy and Pomati 2015; Guio et al. 2017). In contrast, indices like the Multidimensional Poverty Index (Alkire and Santos 2010), inspired by the Capabilities Approach, have generally used the availability of indicators in the Demographic and Health Surveys (DHS), the Multiple Indicator Cluster Surveys (MICS) and the World Health Surveys (WHS) appealing to the instrumental value and appeal of health, education and basic living standards (cooking fuel, sanitation, water, electricity, floors and basic household assets), with less concern given to issues of reliability and additivity. These differences will inevitably lead to differences in how indices and measures are constructed, aggregated and then estimated.

Despite this, it is self-evident that most approaches to poverty can (and should) arguably benefit from the process of consulting the public over necessities. The responses to questions 


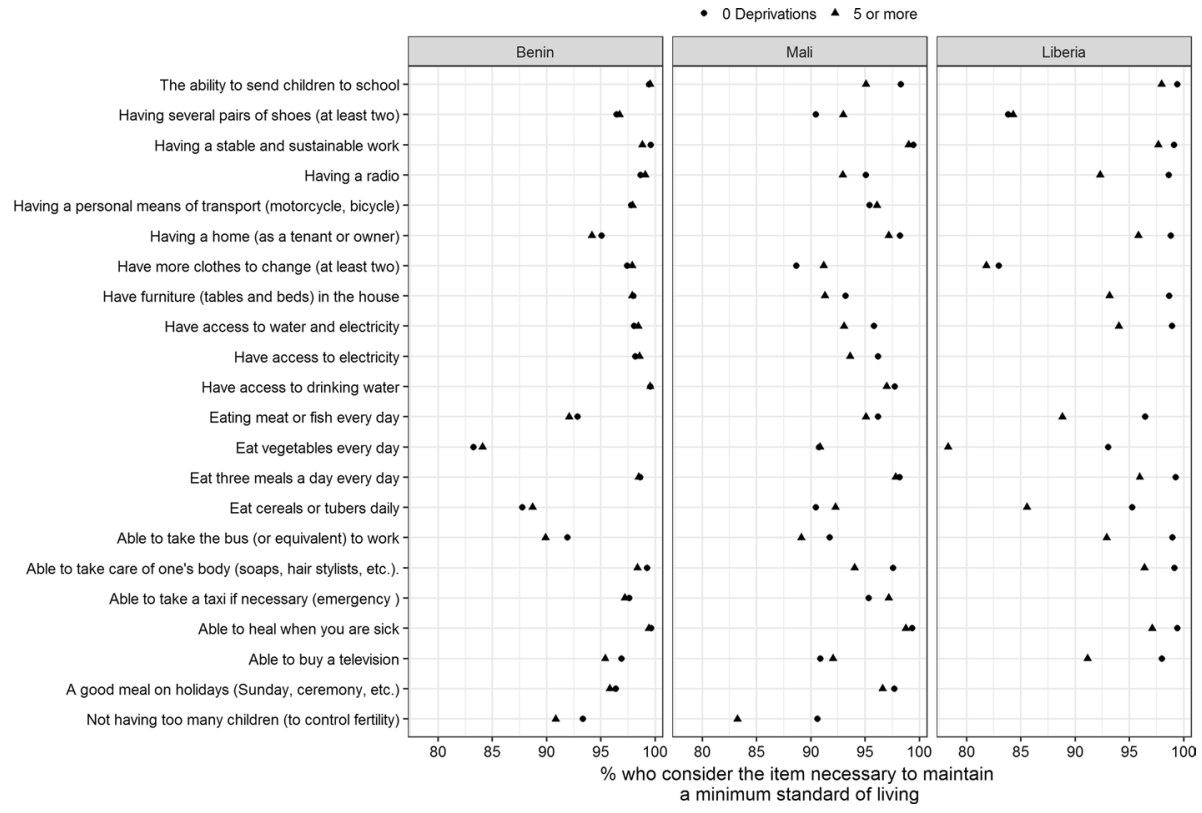

Fig. 7 Percentage who consider item a necessity according to number of deprivations

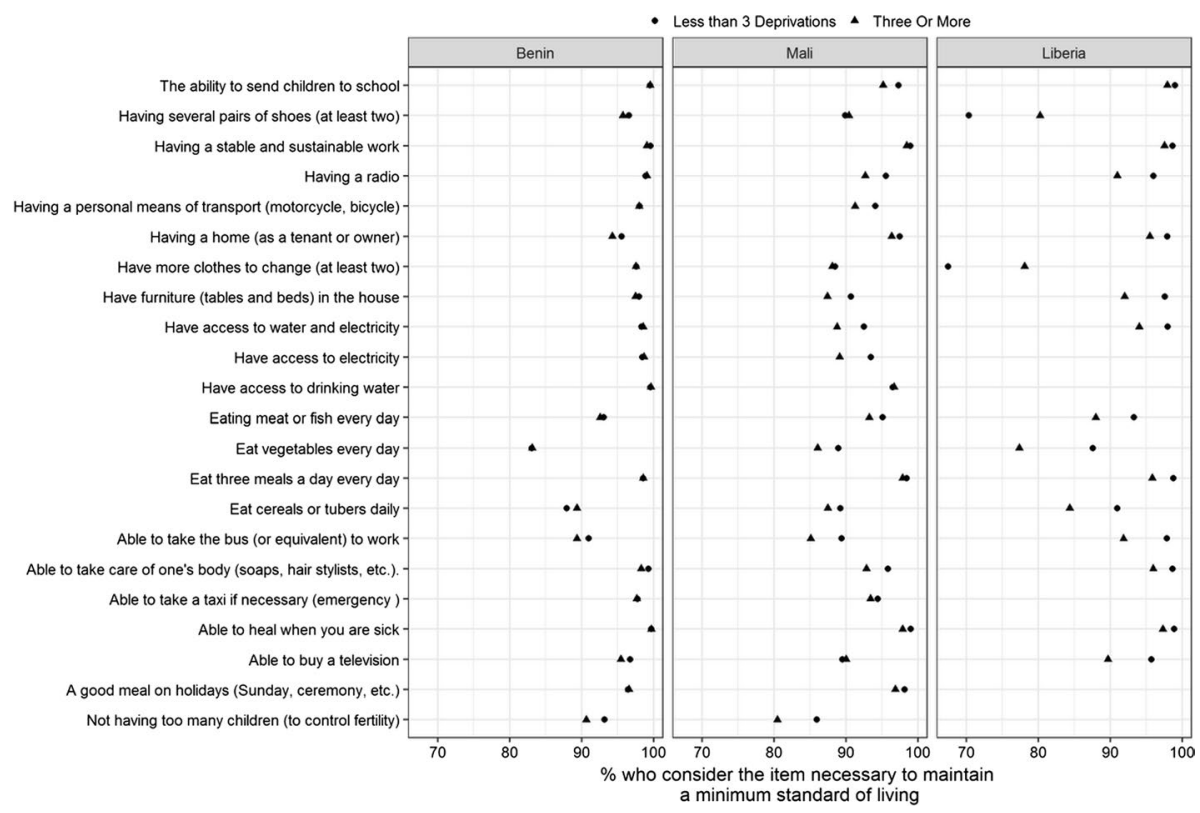

Fig. 8 Percentage who consider item a necessity according to number of deprivations using a cut-off of three deprivations 
on water and electricity shown in Figs. 1 and 2 point to established ideas of basic assets and services which are already included in indices like the MPI (Alkire and Santos 2010, 2014), the Bristol Deprivations Approach (Gordon et al. 2003), UNICEF's Multiple Overlapping Deprivations Approach (De Neubourg et al. 2013) and the Consensual Approach (Noble et al. 2004; Nandy and Pomati 2015). Figure 2 also points to the importance of celebrations and the ability to take part in customary social activities (e.g. having a good meal on special occasions, being able to afford toiletries and other personal care items). Figure 2 also shows demand for food security measures which go beyond detecting undernourishment in the household. These include for example daily consumption of protein and vegetables, which suggests that calorie-based and undernourishment are too narrow a focus for socially realisitic poverty measures. From a Capabilities perspective, Fig. 3 also shows the demand for the ability and resources to prevent one's health from restricting one's freedom and to exert agency over one's reproductive abilities. Similarly, the other questions show demand for the ability to educate oneself and have sustainable work as well as the ability to be where one can carry out valued daily and emergency activities (e.g. providing care of relatives). Overall, whatever the approach, the data presented have clear implications for the understanding of poverty across all its many dimensions, as well for the related demands for public and social policy (health, education, transport policies) and levels of resources (with implications for both personal levels of resources, growth and redistribution).

Our analysis demonstrates a high degree of consensus and agreement about what constitutes a minimum standard of living. The Consensual Approach therefore provides a useful and reliable means for generating data about nationally-defined measures of multidimensional poverty, as required by SDG target 1.2.

There remain potential issues with the way these items were initially selected in the CWIQ surveys (information which we were unable to obtain) and whether the phrasing of the questions on health, school and work, transport, water and electricity could be improved by specifying whether these should be provided as public goods. Deprivation could then be identified as either deprivation due to insufficient resources (cannot afford) or lack of provision (not available, see Fig. 1, Stage 2). However, it could also be argued that the current generic phrasing (e.g. having access to drinking water) focuses on needs (the objective of poverty measurement) rather than how these needs are met, which can arguably make agreement between people of different political leanings easier to reach. Similarly, including specific questions (as for example in the case of three food items: eating meat or fish, vegetables or cereals or tubers daily) as well as more general ones (three meals a day) may help analyse support among similar and different groups and countries respectively. Ultimately these issues can be explored empirically, and the Consensual Approach entails a qualitative stage of focus group discussions as well as questionnaire cognitive interviewing to tackle these important issues (for a UK example see Fahmy, Sutton and Pemberton 2015; for South Africa see Barnes and Wright 2012).

Several countries are going beyond what was done in CWIQ surveys, to ask questions with regards to the needs of children and adults separately, which, again, is what SDG target 1.2 requires. This is happening in the South Pacific (Solomon Islands, Tonga, Tuvalu, Kiribati), and in Uganda, where the 2017 National Household Survey included a module of questions that use the Consensual Approach - a full list of items for children and adults included in the 2017 National Household Survey for Uganda is included in the Appendix (Tables 2 and 3).

Well-established research programmes from different academic fields (e.g. the METAGORA (OECD 2008) and AFROBAROMETER projects, www.afrobarometer. org) have contributed to our understanding of people's perceptions of democracy, corruption and human rights in Africa, their (dis)satisfaction with government provision 
of basic services, and their own economic and political priorities. Other survey programmes like UNICEF's MICS (MICS, www.childinfo.org) and the USAID-funded DHS (DHS, www.measuredhs.com) collect valuable information about people's living conditions, and are increasingly being used to study multidimensional poverty (Gordon et al. 2003; Nandy and Gordon 2009; Alkire and Santos 2010), and also the links between poverty and other issues, such as quality of governance (Halleröd et al. 2013). The addition of a short module of questions, to elicit consensus about living standards and people's expectations, to platforms like DHS and MICS would aid future assessments of multidimensional poverty for the SDGs.

\section{Conclusions}

Extreme poverty remains a global challenge, which the SDGs recognise. In calling for the eradication of poverty 'in all its dimensions', SDG target 1.2 goes beyond the MDGs, requiring governments and international organisations to collect and disaggregate data on poverty, based on national definitions. Increasingly, studies are confirming that there is widespread agreement among the publics in different countries about the necessities of life, or minimum standards of living. Our analyses demonstrate it should be possible to develop agreed international standards and norms for items which reflect a minimally acceptable standard of living that applies within and across countries. We have restricted this paper to the measurement of standards and norms rather than the actual construction of a deprivations-based poverty line. We did so because while the development of multidimensional poverty indices has received much attention, often research applications are unclear about the reasons behind the inclusion of certain non-monetary poverty indicators. In the context of the SDG poverty targets we argue that attention should be placed on how consensus can be achieved, and reflected, about the legitimacy of certain indicators (be they rights-based, consumption deprivation, or a lack of access to basic services) rather than focusing solely on combining these into a single headline figure.

No doubt there is scope for the Consensual Approach to evolve, particularly in being transparent about which necessities are considered. Recent studies and surveys in South Africa, the South Pacific and Uganda have been more explicit in covering children's needs-e.g. by asking about items such as educational toys, books appropriate for children of different ages, and even pocket money.

While each of the studies run in low income countries has successfully demonstrated the merits of the Consensual Approach, each is only a single country study. What would be valuable is a cross-national study, which uses the same (or similar) survey instrument across a set of low income countries. Our paper shows it would be possible to include specific items for a national measure as well as more generic ones (e.g. three meals a day) for international ones. Such data would show whether consensus exists across societies about what people consider to be essential/necessary for a 'decent' standard of living, or in the words of the SDGs, what poverty 'in all its dimensions' looks like. This 'decent' standard of living is not limited to people's ability to access goods and services through the market; it could potentially also include entitlements established in human rights agreements and basic needs for which market-based provision may not be possible. This would then form the basis of a nationally agreed, democratic definition of multidimensional poverty as well as provide a comparable number of poverty dimensions across all countries. 
Open Access This article is distributed under the terms of the Creative Commons Attribution 4.0 International License (http://creativecommons.org/licenses/by/4.0/), which permits unrestricted use, distribution, and reproduction in any medium, provided you give appropriate credit to the original author(s) and the source, provide a link to the Creative Commons license, and indicate if changes were made.

\section{Appendix}

\section{See Tables 2 and 3.}

Table 2 Items and activities for children, in Uganda 2016/17 National Household Survey. Source: Uganda Bureau of Statistics (2016) The Uganda National Household Survey 2016/17-Socio-Economic Survey Questionnaire, Sect. 12B. UBOS, Kampala, Uganda

\section{SECTION 12B: CONSENSUAL POVERTY}

\section{CHILD ITEMS (ANY ONE BELOW 18 YEARS OF AGE)}

Please say whether you think each of the following is essential for everv parent or caregiver to be able to afford for children they care for in order for them to enjoy an acceptable standard of living in Uganda today. If you think it is essential please say 'ESSENTIAL'. If you think it is desirable but not essential please say 'DESIRABLE', If you think it is not essential and not desirable please say 'NEITHER'. So the three possible answers are 'ESSENTIAL', 'DESIRABLE' or 'NEITHER'.

\begin{tabular}{|c|c|c|c|c|c|c|c|c|c|}
\hline Item & Essential & $\begin{array}{c}\text { Desirable, } \\
\text { but not } \\
\text { essential }\end{array}$ & Neither & DK & $\begin{array}{l}\text { Have } \\
\text { it }\end{array}$ & $\begin{array}{l}\text { Don't have, } \\
\text { can't afford }\end{array}$ & $\begin{array}{c}\text { Don't } \\
\text { have, don't } \\
\text { want }\end{array}$ & $\begin{array}{c}\text { Don't have, } \\
\text { for another } \\
\text { reason }\end{array}$ & DK/NA \\
\hline QC1 Three meals a day & 1 & 2 & 3 & 8 & 1 & 2 & 3 & 4 & 8 \\
\hline $\begin{array}{l}\text { QC2 Two pairs of properly fitting shoes, including a pair of all-weather } \\
\text { shoes }\end{array}$ & 1 & 2 & 3 & 8 & 1 & 2 & 3 & 4 & 8 \\
\hline QC3 Toiletries to be able to wash every day (e.g. soap, hairbrush/comb) & 1 & 2 & 3 & 8 & 1 & 2 & 3 & 4 & 8 \\
\hline $\begin{array}{l}\text { QC4 Books at home suitable for their age (including reference and story } \\
\text { books) }\end{array}$ & 1 & 2 & 3 & 8 & 1 & 2 & 3 & 4 & 8 \\
\hline QC5 Some new clothes (not second hand or handed on/down) & 1 & 2 & 3 & 8 & 1 & 2 & 3 & 4 & 8 \\
\hline QC6 Educational toys and games & 1 & 2 & 3 & 8 & 1 & 2 & 3 & 4 & 8 \\
\hline $\begin{array}{l}\text { QC7 A visit to a health facility when ill and all the medication prescribed } \\
\text { to treat the illness }\end{array}$ & 1 & 2 & 3 & 8 & 1 & 2 & 3 & 4 & 8 \\
\hline QC8 Own bed & 1 & 2 & 3 & 8 & 1 & 2 & 3 & 4 & 8 \\
\hline QC9 Own blanket & 1 & 2 & 3 & 8 & 1 & 2 & 3 & 4 & 8 \\
\hline QC10 Two sets of clothing & 1 & 2 & 3 & 8 & 1 & 2 & 3 & 4 & 8 \\
\hline $\begin{array}{l}\text { QC11 Presents for children once a year on special occasions, e.g. } \\
\text { birthdays, Christmas, Eid }\end{array}$ & 1 & 2 & 3 & 8 & 1 & 2 & 3 & 4 & 8 \\
\hline $\begin{array}{l}\text { QC12 All fees, uniform of correct size and equipment required for school } \\
\text { (e.g, books, school bag, lunch/lunch money, stationery) }\end{array}$ & 1 & 2 & 3 & 8 & 1 & 2 & 3 & 4 & 8 \\
\hline QC13 To be able to participate in school trips or events that cost money & 1 & 2 & 3 & 8 & 1 & 2 & 3 & 4 & 8 \\
\hline QC14 A desk and chair for homework for school aged children & 1 & 2 & 3 & 8 & 1 & 2 & 3 & 4 & 8 \\
\hline QC15 Bus/taxi fare or other transport (e.g. bicycle) to get to school & 1 & 2 & 3 & 8 & 1 & 2 & 3 & 4 & 8 \\
\hline QC16 Own room for children over 10 of different sexes & 1 & 2 & 3 & 8 & 1 & 2 & 3 & 4 & 8 \\
\hline QC17 Some fashionable clothes for secondary school aged children & 1 & 2 & 3 & 8 & 1 & 2 & 3 & 4 & 8 \\
\hline QC18 Own cell phone for secondary school aged children & 1 & 2 & 3 & 8 & 1 & 2 & 3 & 4 & 8 \\
\hline
\end{tabular}

Table 3 Items and activities for all household members and adults, in Uganda 2016/17 National Household Survey. Source: Uganda Bureau of Statistics (2016) The Uganda National Household Survey 2016/17Socio-Economic Survey Questionnaire, Sect. 12B. UBOS, Kampala, Uganda

\section{HOUSEHOLD ITEMS (relevant to all household members)}

Please say whether you think each of the following is essential for everyone to be able to afford in order for them to enioy an acceptable standard of living in Uganda today. If you think it is essentia please say 'ESSENTIAL'. If you think it is desirable but not essential please say 'DESIRABLE'. If you think it is not essential and not desirable please say 'NEITHER'. So the three possible answers are (DESIRABLE' or 'NEITHER

\begin{tabular}{|c|c|c|c|c|c|c|c|c|c|}
\hline Item & Essential & $\begin{array}{c}\text { Desirable, } \\
\text { but not } \\
\text { essential } \\
\end{array}$ & Neither & DK & $\begin{array}{c}\text { Have } \\
\text { it }\end{array}$ & $\begin{array}{l}\text { Don't have, } \\
\text { can't afford }\end{array}$ & $\begin{array}{l}\text { Don't have, } \\
\text { don't want }\end{array}$ & $\begin{array}{c}\text { Don't have, } \\
\text { for another } \\
\text { reason }\end{array}$ & DK/NA \\
\hline QH1 Enough money to repair or replace any worn out furniture & 1 & 2 & 3 & 8 & 1 & 2 & 3 & 4 & 8 \\
\hline $\begin{array}{l}\text { QH2 Enough money to repair or replace broken electrical goods, e.g. a } \\
\text { refrigerator }\end{array}$ & 1 & 2 & 3 & 8 & 1 & 2 & 3 & 4 & 8 \\
\hline QH3 To be able to make regular savings for emergencies & 1 & 2 & 3 & 8 & 1 & 2 & 3 & 4 & 8 \\
\hline QH4 To be able to replace broken pots and pans for cooking & 1 & 2 & 3 & 8 & 1 & 2 & 3 & 4 & 8 \\
\hline QH5 Enough money to repair a leaking roof for the main living quarters & 1 & 2 & 3 & 8 & 1 & 2 & 3 & 4 & 8 \\
\hline QH6 Have your own means of transportation (e.g. car, bike, motorcycle, etc) & 1 & 2 & 3 & 8 & 1 & 2 & 3 & 4 & 8 \\
\hline
\end{tabular}

\section{ADULT ITEMS (relevant to household members aged 18+)}

Please say whether you think each of the following is essential for every adult (18+ years) to be able to afford in order for them to enjoy an acceptable standard of living in Uganda today. If you think it is essential please say
'ESSENTIAL', If you think it is desirable but not essential please say 'OESIRABLE'. If you think it is not essential and not desirable please say 'NEITHER'. So the three possible answers are 'ESSENTIAL', 'OESIRABL' of 'NEITHER"

\begin{tabular}{|c|c|c|c|c|c|c|c|c|c|}
\hline Item & Essential & $\begin{array}{l}\text { le, but not } \\
\text { ential }\end{array}$ & Neither & DK & $\begin{array}{c}\text { Have } \\
\text { it }\end{array}$ & $\begin{array}{l}\text { Don't have, } \\
\text { can't afford }\end{array}$ & $\begin{array}{l}\text { Don't have, } \\
\text { don't want }\end{array}$ & $\begin{array}{l}\text { Don't have, } \\
\text { for another } \\
\text { reason }\end{array}$ & DK/NA \\
\hline $\begin{array}{l}\text { QA1 A visit to a health facility when ill and all the medication prescribed to } \\
\text { treat the illness }\end{array}$ & 1 & 2 & 3 & 8 & 1 & 2 & 3 & 4 & 8 \\
\hline QA2 Toiletries to be able to wash every day (e.g. soap, hairbrush/comb) & 1 & 2 & 3 & 8 & 1 & 2 & 3 & 4 & 8 \\
\hline QA3 Two pairs of properly fitting shoes, including a pair of all-weather shoes & 1 & 2 & 3 & 8 & 1 & 2 & 3 & 4 & 8 \\
\hline QA4 A small amount of money to spend each week on yourself & 1 & 2 & 3 & 8 & 1 & 2 & 3 & 4 & 8 \\
\hline QA5 Replace worn-out clothes by some new (not second-hand) ones & 1 & 2 & 3 & 8 & 1 & 2 & 3 & 4 & 8 \\
\hline $\begin{array}{l}\text { QA6 To get together with friends/family (relatives) for a drink/meal at least } \\
\text { once a month }\end{array}$ & 1 & 2 & 3 & 8 & 1 & 2 & 3 & 4 & 8 \\
\hline QA7 Celebrations on special occasions, such as Christmas, Eid. & 1 & 2 & 3 & 8 & 1 & 2 & 3 & 4 & 8 \\
\hline QA8 Attend weddings, funerals and other such occasions & 1 & 2 & 3 & 8 & 1 & 2 & 3 & 4 & 8 \\
\hline QA9 Able to access to safe, reliable public transport, such as buses and boats & 1 & 2 & $\frac{3}{3}$ & 8 & 1 & 2 & $\frac{3}{3}$ & $\frac{4}{4}$ & 8 \\
\hline QA10 Enough money to pay school fees for children & 1 & 2 & 3 & 8 & 1 & 2 & 3 & 4 & 8 \\
\hline QA11 Enough money to take children to a medical facility when sick & 1 & 2 & 3 & 8 & 1 & 2 & 3 & 4 & 8 \\
\hline
\end{tabular}




\section{References}

Abe, A. (2004). Saiteigen no Seikatsu Suijun ni Kansuru Shakaiteki Hyoka [Public opinion of minimum standard of living]. Kikan Shakai Hosho Kenkyu [Journal of Social Security Research], 39(4), 403-414.

Abe, A., \& Pantazis, C. (2013). Comparing Public Perceptions of the Necessities of Life across Two Societies: Japan and the United Kingdom. Social Policy and Society, 13(1), 69-88.

Ajayi, O. O. (2006). Experiences in the Application of the Core Welfare Indicator Questionnaire (CWIQ) Survey Technology in Africa: The Journey So Far. The African Statistical Journal/Le Journal Statistique Africain, 3, 189-210.

Alkire, S., \& Santos, M. E. (2010). Acute multidimensional poverty: A new index for developing countries. OPHI Working Paper Nr. 38. Oxford: Oxford University.

Alkire, S., \& Santos, M. E. (2014). Measuring acute poverty in the developing world: Robustness and scope of the multidimensional poverty index. World Development, 59, 251-274.

Alvaredo, F., Chancel, L., Piketty, T., Saez, E., \& Zucman, G. (2018). World Inequality Report. Cambridge: Belknap Press of Harvard University Press.

Anand, S., Segal, P., \& Stiglitz, J. E. (Eds.). (2010). Debates on the measurement of global poverty. Oxford: Oxford University Press.

Baffoe, G., \& Matsuda, H. (2017a). An empirical assessment of households' livelihood vulnerability: The case of rural Ghana. Social Indicators Research, 140(3), 1225-1257.

Baffoe, G., \& Matsuda, H. (2017b). An empirical assessment of rural livelihood assets from gender perspective: Evidence from Ghana. Sustainability Science, 12(3), 815-828.

Barnes, H., \& Wright, G. (2012). Defining child poverty in South Africa using the socially perceived necessities approach. In A. Minujin \& S. Nandy (Eds.), Global child poverty and well-being: Measurement, concepts, policy and action. Bristol: The Policy Press.

Booth, C. (1893). Life and labour of the people in London: First results of an enquiry based on the 1891 census. Journal of the Royal Statistical Society, LIV(IV), 600-643.

Bradshaw, J. (2016). The wellbeing of children in the UK. Bristol: The Policy Press.

Burchardt, T. (2004). Are one man's rags another man's riches? Identifying adaptive expectations using panel data. London: Academic Press.

Chandy, L., \& Gertz, G. (2011). Poverty in numbers: The changing state of global poverty from 2005 to 2015. Washington D.C.: Brookings Institute.

Chase, E., \& Walker, R. (2013). The co-construction of shame in the context of poverty: Beyond a threat to the social bond. Sociology, 47(4), 739-753.

Chzhen, Y., \& Ferrone, L. (2017). Multidimensional child deprivation and poverty measurement: Case study of Bosnia and Herzegovina. Social Indicators Research, 131(3), 999-1014.

Council Decision (1975). 75/458/EEC of 22nd July 1975-Concerning a programme of pilot schemes and studies to combat poverty. In European Commission (ed) OLJ 99/3430.7.75.

Davies, R., \& Smith, W. (1998). The basic necessities survey: The experience of action aid in vietnam. London: Action Aid.

De Neubourg, C., Chai, J., de Milliano, M., \& Plavgo, I. (2013). Step-by-step guidelines to the multiple overlapping deprivation analysis (MODA). UNICEF Office of Research Working Paper. WP-2012-10. Florence: UNICEF Office of Research-Innocenti.

EEC (1985). On specific Community action to combat poverty (Council Decision of 19 December, 1984) 85/8/E.E.C. Official Journal of the European Communities, 2/24.

Eurostat,. (2012). Measuring material deprivation in the EU: Indicators for the whole population and childspecific indicators. Luxembourg: Publications Office of the European Union.

Fahmy, E., Sutton, E., \& Pemberton, S. (2015). Determining the 'necessities of life' in the 2012 PSE-UK survey. In L. Camfield \& K. Roelen (Eds.), Mixed methods in Poverty Research: Advancing the Art. London: Palgrave.

Fajth, G., Kurukulasuriya, S., \& Engilbertsdottir, S. (2012). A Multidimensional response to tackling child poverty and disparities: Reflections from the global study on child poverty and disparities. In A. Minujin \& S. Nandy (Eds.), Global child poverty and well-being: Measurement, concepts, policy and action (pp. 525-543). Bristol: The Policy Press.

Gordon, D., \& Nandy, S. (2012). Measuring child poverty and deprivation. In A. Minujin \& S. Nandy (Eds.), Global child poverty and well-being: Measurement, concepts, policy and action (pp. 57-101). Bristol: The Policy Press.

Gordon, D., Nandy, S., Pantazis, C., Pemberton, S., \& Townsend, P. (2003). Child poverty in the developing world. Bristol: The Policy Press.

Gordon, D., \& Townsend, P. (2000). Breadline Europe: The measurement of poverty. Bristol: Policy Press. 
Guio, A. C., Gordon, D., Najera, H., \& Pomati, M. (2017). Revising the EU material deprivation variables. Luxembourg: European Union.

Gursky, D. B., \& Kanbur, R. (Eds.). (2006). Poverty and inequality. Stanford: Standford University Press.

Hall, A. J., \& Midgley, J. (2004). Social policy for development. London: Sage Publications Ltd.

Hallerod, B. (1994). A new approach to direct consensual measurement of poverty. University of New South Wales: Social Policy Research Centre.

Hallerod, B. (1995). The truly poor: Indirect and direct measurement of consensual poverty in Sweden. Journal of European Social Policy, 5(2), 111-129.

Halleröd, B. (2006). Sour grapes: Relative deprivation, adaptive preferences and the measurement of poverty. Journal of Social Policy, 35(3), 371-390.

Halleröd, B., Bradshaw, J., \& Holmes, H. (1997). Adapting the consensual definition of poverty. In D. Gordon \& C. Pantazis (Eds.), Breadline Britain in the 1990s. Aldershot: Ashgate.

Halleröd, B., Larsson, D., Gordon, D., \& Ritakallio, V. M. (2006). Relative deprivation: A comparative analysis of Britain, Finland and Sweden. Journal of European Social Policy, 16(4), 328-345.

Halleröd, B., Rothstein, B., Adel, D., \& Nandy, S. (2013). Bad governance and poor children: A comparative analysis of government efficiency and severe child deprivation in 68 low- and middle-income countries. World Development, 48, 19-31.

Hunt, J., Bessell, S., Crawford, J., Fisk, K., Nguyen, H., Pham, T., et al. (2017). The individual deprivation measure: Methodology update 2017, Australian National University. Melbourne: Canberra and International Women's Development Agency.

Iliffe, J. (1987). The African poor: A history. Cambridge: Cambridge University Press.

INSAE. (2007). Enquete modulaire integree sur les conditons de vie des menages (EMICov) Benin. Cotonou, Benin: INSAE.

Jerven, M. (2013). Poor numbers: How we are misled by African development statistics and what to do about it. Ithaca: Cornell University Press.

Kaijage, F., \& Tibaijuka, A. (1996). Poverty and social exclusion in Tanzania. Geneva: ILS.

Kim, E., \& Nandy, S. (2018). Multidimensional child poverty in Korea: Developing child-specific indicators for the sustainable development goals. Child Indicators Research, 11(3), 1029-1050.

Kingdon, G., \& Knight, J. (2006). Subjective well-being poverty vs. income poverty and capabilities poverty? Journal of Development Studies, 42(7), 1199-1224.

Klasen, S. (2000). Measuring poverty and deprivation in South Africa. Review of Income and Wealth, 46(1), 33-58.

Mack, J., \& Lansley, S. (1985). Poor Britain. London: Allen and Unwin.

Mahbub Uddin Ahmed, A. I. (2007). Consensual poverty in Britain, Sweden and Bangladesh: A comparative study. Bangladesh e-Journal of Sociology, 4(2), 56-77.

Mckay, S. (2004). Poverty or preference: What do 'consensual deprivation indicators' really measure? Fiscal Studies, 25(2), 201-223.

Mtapuri, O. (2011). Developing and asset threshold using the consensual approach: Results from Mashonaland West, Zimbabwe. Journal of International Development, 23, 29-41.

Nandy, S., \& Gordon, D. (2009). Children living in squalor: shelter, water and sanitation deprivations in developing countries. Children, Youth and Environments, 19(2), 202-228.

Nandy, S., \& Pomati, M. (2015). Applying the consensual method of estimating poverty in a low income African setting. Social Indicators Research, 124(3), 693-726.

Naoroji, D. (1901). Poverty and Un-British rule in India. London: Swan Sonnenschein \& Co., Ltd.

Narayan, D., Chambers, R., Shah, M. K., \& Petesch, P. (2000). Voices of the poor volume I can anyone hear us ? Voices from 47 countries, World Bank, Washington DC. Retrived http://siteresources.worldbank. org/BRAZILINPOREXTN/Resources/3817166-1185895645304/4044168-1186324101142/17voices_ of_the_poor_1.pdf.

Noble, M., Ratcliffe, A., \& Wright, G. (2004). Conceptualizing, defining and measuring poverty in South Africa: An argument for a consensual approach. Oxford: Centre for the Analysis of South African Social Policy, University of Oxford.

NSIA. (2019). Afghanistan multidimensional poverty index 2016-2017. Kabul: NSIA.

Nteziyaremye, A., \& Mknelly, B. (2001). Mali poverty outreach study of the Kafo Jiginew and Nyesigiso credit and savings with education programs. CA: Davis.

Nussbaum, M. (1999). Sex and social justice. New York: Oxford University Press.

OECD. (2008). Measuring human rights and democratic governance: Experiences and lessons from Metagora. OECD Journal on Development, 9(2), 1-37.

Piachaud, D. (1987). Problems in the definition and measurement of poverty. Journal of Social Policy, 16(2), 147-164. 
Reddy, S. \& Pogge, T. (2010). How not to count the poor. In S. Anand, P. Segal \& J. Stiglitz (Eds.), Debates on the measurement of global poverty.Oxford: Oxford University Press New York.

Rowntree, S. B. (1901). Poverty: A study of town life. London: Macmillan.

Sahn, D., \& Younger, S. D. (2010). Living standards in Africa. In S. Anand, P. Segal, \& J. E. Stiglitz (Eds.), Debates on the measurement of global poverty (pp. 372-425). Oxford: Oxford University Press.

Sala-I-Martin, X. \& Pinkovskiy, M. (2010). African poverty is falling... Much faster than you think. Cambridge: National Bureau of Economic Research(NBER) Working Paper 15775

Saunders, P. (2011). Down and out: Poverty and exclusion in Australia. Bristol: The Policy Press.

Saunders, P., Naidoo, Y., \& Megan, G. (2008). Towards new indicators of disadvantage: Deprivation and social exclusion in Australia. The Australian Journal of Social Issues, 43(2), 175-194.

Sen, A. (1987). The standard of living. Cambridge: Cambridge University Press.

Sen, A. (1999). Development as freedom. Oxford: Oxford University Press.

Statistics South Africa (2012). Subjective poverty in South Africa: Findings of the living conditions survey 2008/2009. Pretoria.

Townsend, P. (1954). Measuring poverty. British Journal of Sociology, 5(2), 130-137.

Townsend, P. (1970). The concept of poverty. London: Heinemann.

Townsend, P. (1979). Poverty in the United Kingdom. Harmondsworth: Penguin Books Ltd.

Townsend, P., Gordon, D., \& Pantazis, C. (2006). The international measurement of 'absolute' and 'overall' poverty: Applying the 1995 Copenhagen definitions to Britain. In C. Pantazis, D. Gordon, \& R. Levitas (Eds.), Poverty and social exclusion in Britain: The Millennium survey. Bristol: The Policy Press.

UNDP (2019). Sierra leone multidimensional poverty index. Freetown: UNDP Sierra Leone.

United Nations (1995). The Copenhagen declaration and programme of action: world summit for social development 6-12 March 1995. New York.

United Nations (2015). The Millennium Development Goals Report 2015. New York City.

Valadez-Martínez, L., Padley, M., \& Torres Penagos, M. F. (2018). A dignified standard of living in Mexico: Results of a pilot study of the minimum income standard approach. Social Indicators Research, 140, 695.

Van Den Bosch, K. (2001). Indentifying the poor: Using subjective and consensual measures. Aldershot: Ashgate.

Vandemoortele, J. (2002). Are we really reducing global poverty? In P. Townsend \& D. Gordon (Eds.), World Poverty: New policies to defeat an old enemy. Bristol: The Policy Press.

Veit Wilson, J. (1987). Consensual approaches to poverty lines and social security. Journal of Social Policy, $16(2), 183-211$.

Walker, R. (1987). Consensual approaches to the definition of poverty: Towards an alternative methodology. Journal of Social Policy, 16(2), 213-225.

Wisor, S., Bessel, S., Castillo, F., Crawford, J., Donaghue, K., Hunt, J., et al. (2016). The individual deprivation measure: A gender-sensitive approach to poverty measurement-updated version. Melbourne: International Women's Development Agency.

World Bank (2016). Monitoring Global Poverty: Report of the Commission on Global Poverty. Washington D.C.

Wright, G. (2008). Findings from the indicators of poverty and social exclusion project: A profile of poverty using the socially perceived necessities approach: Key Report 7. Pretoria.

Wright, G., \& Noble, M. (2013). Does widespread lack undermine the socially perceived necessities approach to defining poverty? Evidence from South Africa Journal of Social Policy, 42(1), 147-165.

Publisher's Note Springer Nature remains neutral with regard to jurisdictional claims in published maps and institutional affiliations. 